\title{
Música y palabras en Nietzsche: Sobre la cuestión de la ciencia, el estilo y la música de la tragedia antigua ${ }^{1}$
}

\author{
BABETTE E. BABICH \\ Universidad Fordham, Nueva York
}

\section{NIETZSCHE COMO ERA ANTES Y COMO PENSADOR FUTURO - NIETZSCHE UND KEIN ENDE!}

En el pasado estaba de moda enfatizar el estatus póstumo de la fama demasiado actual de Nietzsche. Así, se deleitaban recordando que Nietzsche mismo había predicho su destino como 'póstumo'. La idea ingeniosa era que los lectores para quienes había sido escrita su filosofía todavía no habían nacido cuando él escribía, y la consecuencia ya no tan sutil era que los lectores actuales estarían especialmente destinados a su pensamiento. De este modo, esos autores que rutinariamente escriben libros sobre Nietzsche nos recuerdan que fue recibido pobremente en su época, contrastando esta supuesta pobre recepción con su remarcable popularidad de hoy en día. La consecuencia, que no vamos a discutir aquí, es que Nietzsche era sencillamente un adelantado a su tiempo y que los oídos modernos, nuestros oídos, eran los oídos para los que él tenía algo que decir. En el lenguaje del pensamiento 'póstumo', Nietzsche estaba destinado a ser entendido.

Seguramente una gran parte de este análisis es correcto y Nietzsche es uno de esos raros filósofos que apelan a un rango inaudito de lectores, tanto de dentro de la filosofía, o de la profesión universitaria, como de fuera. Quizás más interesante que este vasto alcance, es el hecho de que Nietzsche hace esta apelación en su propio nombre, explícitamente, como un novelista que se anunciase como best-

${ }^{1}$ Nota del traductor: Publicamos este artículo en traducción castellana, pero es ésta su primera publicación tanto en castellano como en su lengua original inglesa. Para las citas de textos de Nietzsche hemos seguido el criterio de mantener la versión que ha hecho la autora del alemán al inglés, y dar nosotros a su vez la traducción del inglés. Somos conscientes que no es éste el criterio más ortodoxo, pero creemos que responde mejor a unos mínimos criterios hermenéuticos. $\mathrm{Si}$, como han demostrado grandes pensadores del siglo $\mathrm{XX}$, traducir es ya siempre interpretar, no tiene sentido sacar a colación otra traducción castellana que no responda a la visión global del autor, de modo que se produzcan disfunciones o incongruencias entre lo que dice el autor y la cita (y que, como se ha hecho, haya que remediar luego con notas a pie de página). 
seller antes de su recepción como tal. Más aún, Nietzsche dirige hacia el futuro esas auto-reivindicaciones de confianza, de manera que desde su perspectiva la refutación y la confirmación son igual de superfluas. Muy significativamente, sus predicciones han resultado ser tan certeras que algunos filósofos -también teóricos culturales y políticos- consideran que Nietzsche ofrece indicaciones literales al momento presente, trasformándolo en una especie de último Nostradamus en curso. Deben rechazarse los excesos de esta especie de credulidad demasiado persistente en los estudiosos, que Nietzsche mismo habría puesto bajo sospecha, como hizo en la primera sección del prefacio escrito en 1886 a Humano, demasiado humano -en todo esto hallan eco las famosas tesis de Ricoeur, quien no ha sido el único en tomar prestado el lenguaje de Nietzsche para analizar al mismo Nietzsche. Pero las sospechas de este tipo son últimamente bastante raras y en su lugar los estudiosos se lamentan de que Nietzsche siga siendo casi demasiado cómodo: Nietzsche parece ser casi cualquier cosa para cualquiera².

Muchas de estas lamentaciones expresan distintas versiones de la falta de emancipación filosófica por parte de movimientos filosóficos populares, pero en todo caso ese amplio recurso a Nietzsche tiene que ver con lo que Nietzsche puede hacer con las palabras - un clásico logro retórico alcanzado eficazmente, literalmente, mundos y eones más allá de lo que podía soñar Austin ${ }^{3}$. Este logro no es algo sobre lo que Nietzsche hable o analice, sino algo que Nietzsche puede hacer y ha hecho con las solas palabras.

Los días de su investidura están sobre nosotros, si asumimos, como creo que debiéramos hacer, que el período de mayor influencia suya todavía no ha llegado, pero si asumimos también que ya ha pasado la ampulosidad retórica y el horror demasiado real ante el símbolo imaginario del régimen milenario, símbolo que todavía nos paraliza con sus más de treinta años de herencia de mal, y con una sombra que sigue dominando nuestra visión ética y ha desplazado al fascismo de su lugar hacia el nuevo milenio, cegándonos a la historia, entumeciéndonos frente a sus numerosas, demasiado actuales expresiones.

Y seguramente Nietzsche encaja de cualquier manera. Así, los filósofos de estilo analítico escriben libro tras libro sobre Nietzsche sin demostrar apuro alguno, mientras que los llamados filósofos 'continentales' toman a Nietzsche normalmente como una especie de padre fundador. Pero evidentemente, si es verdad que Nietzsche puede ser leído desde cualquier perspectiva, también es verdad que esas lecturas nos dicen más sobre los lectores, que sobre el autor, quien a su vez nos dice eso mismo, cuando escribe aparentemente su Ecce homo con el fin de declarar la propia emancipación personal: «Yo soy una cosa y otra mis escritos».

\footnotetext{
${ }^{2}$ Éste es un comentario ofrecido constantemente por los estudiosos, straussianos y nostraussianos, analíticos y continentales; lo único que hago aquí es variarlo un poco.

${ }^{3}$ Ésta no es una visión compartida por lectores inspirados en Stanley y Cavell, respondiendo tanto a sus escritos como a su persona.
} 
Conducible a cualquier punto de vista, no es accidental que los estudiosos sigan convencidos de que no hace falta leer nada antes de leer a Nietzsche sencillamente por sí mismos. Se limitan a sumergirse en él, tomando a Nietzsche como una especie de Biblia contemporánea ${ }^{4}$. Y la alusión bíblica es adecuada: los estudiosos que escriben sobre Nietzsche son especialmente propensos a evitar las notas a pie de página que hacen referencia a sus colegas constantemente en aumento. Todo el mundo tiene su propio Nietzsche.

David B. Allison ha reivindicado esto cuando escribe «Nietzsche escribe exclusivamente para ti. No según tú, pero para ti. Para ti, lector. Sólo a ti» ${ }^{5}$. Pero la clave de la compleja manera en que Nietzsche se dirige al lector, a todo lector, a ti, «sólo a ti», es que la sentida intimidad de los escritos de Nietzsche es preternaturalemente promiscua: Nietzsche escribe sus propios libros como Allerweltsbücher, como libros para el mundo entero. Y él mismo nunca deja de expresar su contento por el otro único libro exitoso escrito de la misma manera -y ésta es también la absorción que le produce-: la Biblia misma. El paradigma de todo libro escrito para todo el mundo, incluyendo a todo el mundo, la Biblia, escrito como la palabra de Dios, revela un tipo de texto profundamente personal y democráticamente inclusivo, que habla directamente al lector, pareciendo expresar sus propios y más íntimos deseos. Este logro es de tipo retórico y Nietzsche a veces toma prestado de la Biblia ese estilo capaz de generar tanta confianza en el lector, de manera que a los estudiosos les cuesta trabajo ver dónde su texto se desvía de la Biblia -hasta tal punto que, más bien como teólogos de Tübingen, escondiéndose tras los arbustos a lo largo del Neckar, más de un estudioso de Nietzsche ha ido buscando en la misma Biblia frases que sólo se hallan en Nietzsche-, mientras que otros estudiosos pasan por alto otras referencias, tanto contemporáneas suyas como clásicas ${ }^{6}$. Por esta

\footnotetext{
${ }^{4}$ El resultado es algo más molesto que el «cada cual tiene su Jesús», de modo que la impresión es que cada cual puede llegar a ser autor de otro libro sobre Nietzsche. Me avergonzaría dar una lista de los estudiosos que ilustran este punto, ya que seguro que cualquier lector tiene su propia lista de ejemplos.

${ }^{5}$ Allison, David B., Reading the New Nietzsche, Rowman \& Littlefield, Lanham (MD), 2001, p. 1 .

${ }^{6}$ No hace falta recordar los nombres de Ernst Rhode, Paul Rée, y por supuesto Richard Wagner. En su libro Nietzsche in Context (Ashgate, Aldershot, 2001), Robin Small ha ofrecido un maravilloso trabajo de exploración de algunos contemporáneos de Nietzsche y el número de estudiosos que han delineado otras influencias es, sin exageración, legión en la literatura de comentarios. Para Paul Rée, véase la útil introducción de Robin Small a su traducción de Rée, Paul, Basic writings (Univ. of Illinois Press, Urbana, 2003). Véase también la discusión de Allison sobre Rée, Nietzsche y Lou Salomé en Reading the New Nietzsche. Yo examino la importancia de Rohde para la invocación nietzscheana del imperativo extraído de Píndaro, Werde, der du bist en «Nietzsche's Imperative as a Friend's Encomium: On Becoming the One You Are, Ethics, and Blessing», Nietzsche-Studien, 33, 2003, 29-58. Véase también Cardew, Alan, «The Dioscuri: Nietzshe and Rhode», en Bishop, P. (ed.), Nietzsche and Antiquity, Camden House, Rochester (New York), 2004, pp. 458-473. Entre los 'amigos' de Nietzsche,
} 
razón, es importante resaltar que Nietzsche no limita sus ejercicios bíblicos a un sitio, allí donde parecen más obvios, en Así habló Zaratustra ${ }^{7}$. Por el contrario, probablemente es más característico de los textos apotegmáticos, aforísticos de Nietzsche su carácter parabólico, en el que no está involucrada específicamente la Biblia -lo veremos más abajo-, desde la obra temprana a la tardía, desde la primera de sus Consideraciones intempestivas, hasta Humano, demasiado humano, y hasta incluso el Crepúsculo de los ídolos y El Anticristo ${ }^{8}$.

Por tanto, yo defiendo que el recurso actual a los escritos de Nietzsche no es reducible a la capacidad receptora de nuestra propia respuesta contemporánea a su voz, o, por el lado de Nietzsche, a la convicción histórica de que él era sencillamente, igual que nosotros, un adelantado a su época, más un contemporáneo de la nuestra que un hombre de su época ${ }^{9}$. El que sus lectores tengan una gran capacidad de recepción, el que Nietzsche sea una voz precoz, no se pone en duda en esta caracterización. Mi cuestión se dirige a interrogar por los orígenes del estilo de Nietzsche. Una reflexión de este tipo es necesaria precisamente porque el atractivo de Nietzsche está más que meramente anunciado tal cual, está

yo incluiría también la influencia de Kant y Schopenhauer, además de Goethe y Hölderlin, por no mencionar a Leopardi, Gracián, Maquiavelo, etc. Esta amplitud significa que el círculo de 'amigos' de Nietzsche excedía su círculo inmediato, y refleja una tradición de compañerismo que no sólo en la época era común en Alemania, sino también un lugar común del mundo antiguo. En este extendido espíritu de afinidades intelectuales, Nietzsche apela a Sócrates -aunque de manera invertida y vía Platón- y a Epicuro, pero también podemos rastrear las influencias de Empédocles, Anaximandro, Heráclito, así como de Píndaro, Sófocles, de los sofistas, Epicteto y Marco Aurelio. También está presente Aristóteles, pero como antagonista.

${ }^{7}$ Esto ocurre también, aunque no sólamente, porque Za es un libro que sus contemporáneos vieron como modelado sobre la base de las óperas de Wagner, tal como el estudioso alemán Ernst Bertram nos lo recordó cerca de hace un siglo en su Nietzsche. Versuch einer Mythologie (Helmut Küpper, Berlin, 1918), comenzando con el capítulo titulado «Arion» (pp. $117 \mathrm{ss)}$ ). Véase también la obra del poeta-filósofo y experto positivista Kremer-Marietti, Angèle, L'homme et ses labyrinthes. Essai sur Friedrich Nietzsche (Unions Géneral d'Éditions, Paris, 1972), y su anterior Thèmes et structures dans l'oeuvre de Nietzsche (Lettres Modernes, Paris, 1957). Sorprendentemente la reciente discusión de Paul Loeb de estos mismos temas, Nietzsche-Studien, no hace mención de sus predecesores, a pesar de que esta temática es por supuesto una de las más populares en la recepción cultural internacional de Nietzsche. Para mayor información véase Liebért, Georges, Nietzsche and Music, tr. D. Pelletier - G. Parkes, University of Chicago Press, Chicago, 2003.

${ }^{8}$ La reciente recepción ha comenzado a considerar con más cuidado esta conciencia religiosa, pero este aspecto ya estaba presente desde el principio en la recepción alemana, francesa e inglesa de los escritos de Nietzsche. Aquí no me interesa especialmente la cuestión de las creencias de Nietzsche, cuanto la influencia literaria de ese foco.

${ }^{9} \mathrm{Ni}$ la apelación nietzscheana deriva de la confianza ilustrada de imaginarnos a nosotros mismos emancipados de un pasado supuestamente ignorante, ya que por su parte es más bien lo contrario, la emancipación de la ilustración clásica. En su lugar, es emancipación de lo ordinario y demasiado moderno en una era postmoderna, algo bastante específico al siglo veinte, considerado como una emancipación de lo que es visto como una tontificación generacional, sea la de los años treinta (los veinte en cambio rugieron), o de los cincuenta -los sesenta, se lo imagina uno (es todo una cuestión de imagen) hablan por sí mismos- o los disco-condenados setenta, etc.

Estudios Nietzsche, 4 (2004), ISSN: 1578-6676, pp. 11-35 
calculado con mucho cuidado, este estilo suyo es el producto de un arte literario cumplido. Muy lejos de la espontaneidad y la impetuosidad descuidada en la expresión, atribuida a su estilo escrito, Nietzsche emplea todo el tiempo posible ensayando este arte. Aquí tenemos un hombre que no rehusaba la aplicación o el perfeccionamiento constante y reflexivo sobre los frutos de sus enseñanzas. Así, desde sus comienzos como filólogo, como profesor y escritor, su manera de entender el estilo retórico giró en torno a la cuestión de qué se requeriría para comenzar a decir cosas muy complicadas, es decir, cosas complejas, tanto por sí mismas, como por los lectores dados y por la manera de leer dada de esos lectores. Puede ser muy pertinente el hecho de que Nietzsche no entrara en su cátedra académica de la manera académica ordinaria (sometiendo una tesis a la consideración del profesor, y defendiéndola ante las exigencias de un tribunal). En cambio, Nietzsche comenzó su actividad investigadora, en la tradición universitaria germánica, escribiendo ensayos encargados (por tanto, con la publicación y el reconocimiento asegurados), culminando con la invitación a un nombramiento, articulado en una lectura inaugural y una serie de lecturas públicas sobre la cuestión de los clásicos, que trascienden la disciplina de la profesión de la filología clásica -la precisión histórica y la ejemplaridad histórica, o excelencia formativa, que él enseñó, pero además, quizás más que nada, el arte epistolar que él pulió una y otra vez ${ }^{10}$.

Este estilo dirigido al lector y auto-desconstructivo ${ }^{11}$ puede verse tanto en los libros preparados por Nietzsche para la publicación, como en las distintas versiones de sus cartas ${ }^{12}$. Esto significa que fue bajo la forma de cuidadoso estudioso del arte de la lengua que Nietzsche alcanzó no sólo una maestría teórica, sino también sobre todo -y por esto es la excepción entre los especia-

\footnotetext{
${ }^{10}$ La relevancia de esta formación para su estilo retórico sigue inexplorada, no ha sido ofrecida por Small, Robin, Nietzsche in Context (libro en otros aspectos maravilloso e inapreciable), ni por Porter, James, The Invention of Dionysus: An Essay on the Birth of Tragedy (Stanford University Press, 2000), ni por su libro más amplio Nietzsche and the Philology of the Future (Stanford University Press, 2000), ni tampoco se encuentra allí donde se puede encontrar cualquier otra cosa, en Janz, Curt Paul, Friedrich Nietzsche. Biographie (Zwei Tausend Eins, Frankfurt, 1999), ni tampoco en el cuidadoso estudio de Allison, Reading the New Nietzsche, ni en Nehamas, Alexander, Nietzsche: Life as Literature (Harvard University Press, Cambridge (MA), 1985), ni en los dos volúmenes del Ecce homo de Sarah Kofman, y tanto es así que la temática es obviada -lo que quizás era predecible- en los libros de Werner Ross y Hermann Josef Schmidt -y podemos entonces preguntar cómo habría que empezar a expolorarlo, pues es esta cuestión la que todavía permanece incisiva aún después de tantos años de estudio académico sobre Nietzsche.

${ }^{11}$ Para una discusión de este estilo dirigido al lector y desconstructivo, véase Babich, Babette E., «Nietzsche's Self-Deconstruction: Philosophy as Style», Soundings. 73, 1990, 50-12, y «On Nietzsche's Concinnity: An Analysis of Style», Nietzsche-Studien, 19, 1990, 59-80.

${ }^{12}$ Nietzsche escribía regularmente la misma carta a distintos amigos suyos, lo que no significa que él no las modificara para dirigirse a cada persona individualmente: componiendo un esbozo y luego rescribiéndolo con apropiadas variaciones sobre el mismo tema de base, a sus diferentes correspondientes. Véase KGB.
} 
listas- una maestría práctica en el arte de escribir composiciones de estilo ${ }^{13}$. Esta maestría no necesariamente hace a Nietzsche más fácil de leer, sino que significa que en sus textos hay mucho más que lo manifiesto a primera vista, e incluso después de muchos contactos con sus textos. En parte esto es debido a Nietzsche, en parte a su público.

\section{Cuestionando la ciencia: Sobre el problema} DEL ESTUDIO ACADÉMICO

Podríamos decir que Nietzsche tiene el arte del estilo 'hasta en la ciencia'. Pero esto es más que una metáfora para el Nietzsche que describe el proyecto de cómo plantear la cuestión de la ciencia como tal, cuando pone la cuestión de su propio arte de escribir en el prefacio escrito posteriormente a su primer libro sobre la forma o el estilo trágico, su famoso «Ensayo de autocrítica». Pero reflexionar sobre lo que Nietzsche llama el problema de la ciencia, y sus esfuerzos por plantear precisamente esta cuestión como una cuestión, cuestionando a la ciencia como si fuese por primera vez, nos coge demasiado lejos, demasiado pronto en este punto. En otra parte, he defendido con más detalle que Nietzsche se interesa por la ciencia, desde sus primeros hasta sus últimos escritos, con la atención puesta en la cuestión misma de la ciencia, y también he defendido que este interés no debe ser visto ni como una metáfora ni como literatura, sino como un interés propiamente filosófico, en cuanto fundación de lo que puede ser visto como una genuina (por ser crítica) filosofía de la ciencia. A parte de Heidegger, y con ciertas excepciones, la vasta mayoría de los lectores de Nietzsche se han interesado más en la cuestión moral y en sus vicisitudes, que en los descontentos que produce la cuestión de la verdad o de la ciencia. Si esto está cambiando, no está claro que el cambio vaya en la dirección de aquel mayor enfoque crítico que Heidegger con razón califica de crucial, precisamente porque la interrogación, que tiene que ser puesta en ese tipo de crítica, no lo será siguiendo a Nietzsche, sino al contrario, como Nietzsche sugiere en su propia gaya ciencia, tiene que ser desarrollada y enfocada como el arte de reír, que sería también el arte de una ciencia crítica. Ésta es una interrogación que nosotros planteamos a partir de nosotros mismos. Nosotros necesitamos, como cognoscentes, cierto y constante grado de autocrítica, y precisamente como cognoscentes, esta crítica nos evita.

\footnotetext{
${ }^{13}$ En este contexto, y en contra de la reciente tempestad textual que apareció primero y fue creciendo en los Nietzsche-Studien (véase más abajo la nota 27 para las referencias relevantes), la relevancia de la lectura que hizo Nietzsche del libro de Gustav Gerber Die Sprache als Kunst (2 vols., Mittler'sche Buchhandlung, Bromberg, 1871), cuya gran parte tomaría una forma propia dentro del escrito de Nietzsche (no-publicado) Sobre verdad y mentira en sentido extramoral, está en ser menos un caso de influencia ocultada, que de efectiva relevancia (o de influencia rutinaria) del ejercicio de extracción de un manual reconocido, en una época carente de medios de reproducciones mecánicos o fotocopiadores.
}

Estudios Nietzsche, 4 (2004), ISSN: 1578-6676, pp. 11-35 
En su bien conocido, aunque no publicado en vida, ensayo «Sobre verdad y mentira en sentido extramoral», lo que Nietzsche describe como extramoral -es decir, más allá de culpa y defecto ético, que se convertirá en el dominio de lo que está más allá del bien y del mal- es la naturaleza lógica de la verdad, su referencia metafórica, e incluso, más precisamente, la relación entre verdad y mentira en un sentido observacional, completamente eco-fisiológico ${ }^{14}$. Pero como podemos leer $-\mathrm{y}$ el lector notará que el presente artículo versa mucho más sobre las reacciones que sus lectores tienen frente a Nietzsche, que sobre Nietzsche mismo-, los comentadores, desde Derrida -quien abierta y declaradamente anuncia que su interés es hablar de la mujer- hasta otros autores -quienes hablan variadamente de tropos y metáforas-, han esquivado, casi sin excepción, la cuestión lógica de la verdad y la mentira en su desarrollo positivista ${ }^{15}$. De esta manera, los lectores de Nietzsche saltan cuidadosamente por encima de la referencia al dominio real o empírico de la observación perceptiva, o si no, del contexto de la fisiología humana -se habla en cambio de cuerpo, como una generación previa, inspirada en Merleau-Ponty, hablaba de 'carne'-, o si no, de la fisicalidad contingente del entorno humano, o lo que yo he llamado eco-fisiología -el lenguaje popular de hoy en día invoca con frecuencia 'ecología' y 'medio ambiente', que se hace así conveniente para recalcar el aislamiento de la humanidad física y encarnada con respecto a este mismo Umwelt, casi tan efectivamente como la historia bíblica del Génesis ha subrayado esta separación durante centurias.

Algunos estudiosos han empezado además a tratar las reflexiones nietzscheanas, no en el juego erótico de una lectura desconstructiva, o en las asociaciones libres, por metonimias, de metáforas, sino en términos de una caza de las propias fuentes de Nietzsche. Esta es la nueva 'ciencia' de los estudios sobre Nietzsche, la cual sin embargo no produce automáticamente un Nietzsche cuyo pensamiento sea relevante para la ciencia que cuenta en la cultura global de hoy en día, o en todo caso para las cuestiones sobre la verdad o la epistemología. Los especialistas de esta nueva especie han descubierto la fuente -importante en singular- del escrito de Nietzsche Sobre verdad y mentira en sentido extramoral, y cada vez más los especialistas adiestrados lingüísticamente y los historiadores de las ideas ven esta explicación como la última palabra en la materia. Como si fuera verdad que si nosotros delineamos el estímulo de cualquier observación, negamos con ello la significación filosófica de esa observación, o como Nietzsche mismo argumenta, como si una vez que hemos delineado las

\footnotetext{
${ }^{14} \mathrm{He}$ discutido esta epistemología extramoral en el contexto de la significación, para la filosofía de la ciencia, de la crítica de Nietzsche a la verdad, en mi libro Nietzsche's Philosophy of Science, State University of New York Press, Albany, 1994.

${ }^{15}$ Pero véase para un estudio específico sobre Nietzsche y Comte, en inglés, Allen, Barry, $A$ House Divided: Comparing Continental and Analytic Philosophy, y en francés Angele KrémerMarietti.
} 
influencias originales tras los pensadores pre-platónicos, hubiésemos sacado toda la luz necesaria para entender pensadores como Heráclito, Anaximandro o Empédocles. Por esta razón, Nietzsche empieza su escrito no-publicado, $L a$ filosofía en la época trágica de los griegos, justo con esta cuestión -una cuestión entonces tan antigua y tan actual como lo es hoy en día-, de modo que para explicar el fenómeno del milagro griego, omite esa caza de los rastros de influencias culturales vecinas. Nietzsche argumenta que no era la originalidad sino la habilidad en el aprender lo propio de los griegos, ya que no estaban dotados tanto del genio de la innovación como del genio del aprendizaje. El suyo era un arte auténticamente imitativo, que se ocupa y se sumerge en los descubrimientos de los demás. Los griegos poseían, escribió Nietzsche, «el arte del aprendizaje provechoso» ${ }^{16}$.

Por consiguiente, lo que Nietzsche dice sobre verdad y mentira, en lugar de ser un compromiso glosado con cierto escrito de Gustav Gerber, Die Sprache als Kunst ${ }^{17}$, lo que hace es seguramente, aunque no sólo, replantear el proyecto

${ }^{16}$ Así, aunque en la primera sección de su Philosophie im tragischen Zeitalter der Griechen, Nietzsche enfatizaba el genio griego del comienzo adecuado ( «los griegos sabían cómo comenzar en el momento adecuado» KSA I 805), tuvo cuidado en reconocer «cuánto hallaron los griegos en las extranjeras tierras orientales» (ibid). Por tanto él subrayó la 'tontería' implícita en el intento de atribuir una 'formación autóctona' a los griegos. Pero esto no significa más que los griegos absorbieron las formas de vida extranjeras como una formación viviente: «así ellos avanzaron tan lejos porque donde otro pueblo había abandonado una lanza, ellos sabían cómo retomarla y lanzarla más lejos» (KSA I 806).

${ }^{17}$ En el prefacio a su última edición en un único volumen en 1884, Gerber alude a la filosofía crítica de Kant para conceptualizar su «crítica del lenguaje» como una «Kritik der unreinen Vernunft». Haciendo una alusión comparable en el segundo volumen de la edición de 1871, Gerber parte primeramente de Kant a Lange y Hegel, y luego a Spinoza y Kuno Fischer; una serie de referencias que para algunos estudiosos ha sido suficiente para dar pie a la suposición de que la familiaridad de Nietzsche con estos autores derivaba únicamente de Gerber, igual que algunos bastante atrasados piensan que Nietzsche habría tomado su Kant de segunda mano de Lange o de Schopenhauer. Cualquier cosa que indique esto sobre los hábitos de ciertos estudiosos actuales y de sus relaciones con sus fuentes primarias y secundarias (ésta es una categoría particularmente lábil, dados los textos electrónicos, en cd o on-line que hoy en día pueden buscarse), probablemente no es una base adecuada para sacar una conclusión de ese tipo en el caso de Nietzsche. Porque el propio protocolo de Gerber, normal para el autor de un manual tanto ayer como hoy, era elaborar sus argumentos por medio de referencias familiares. Que estas referencias, antes oportunas y corrientes se conviertan tiempo después en oscuras y completamente invisibles para los lectores posteriores es obvio y una comparable falta de relevancia podía ser, para los lectores anglófonos que quieran emprender la estrategia experimental de consultar el libro de Henry Watson y Francis George Fowler The King's English, publicado por primera vez en 1906. Este último ejemplo es instructivo precisamente porque la ilustraciones de Fowler siguen siendo textos más disponibles para nosotros que la mayor parte de los ejemplos (como hacen las ilustraciones de Gerber) del griego, el latín, el hebreo, el sánscrito, etc. Para una lectura textual de Nietzsche como filósofo del lenguaje, véase Gustafsson, Lars, Sprach und Lüge. Drei sprachphilosophische Extremisten: Friedrich Nietzsche. A. B. Johnson, Fritz Mauthner, Hanser, München, 1980. Nótese que este libro ha tenido poca repercusión, sea en contra que a favor, en contraste con el acumulante torrente de respuestas producidas en la estela literaria de Paul de Man,

Estudios Nietzsche, 4 (2004), ISSN: 1578-6676, pp. 11-35 
de Gerber de un manual de retórica, como algunos estudiosos de la filología contemporánea, delineando la doxografía de los propios textos nietzscheanos, han demostrado. Algunos han resaltado con una gran dosis de justificación, la cual puede hallarse en Nietzsche mismo, que el estímulo para tales investigaciones de las fuentes presupone un ideal de originalidad que no se ha dado nunca en el pasado y que no se sigue dando en el presente.

En realidad, Nietzsche no se limita a referirse al potencial artístico de Die Sprache als Kunst (El lenguaje como arte), sino que busca introducir la cuestión de la verdad y de la mentira en el lenguaje, y de manera bastante importante, conduciendo la cuestión de la verdad en la misma dirección en que lo habría hecho Gerber mismo, en un gesto que parece como si Nietzsche repagara al favor de préstamo, desarrollando las cuestiones acerca del lenguaje y del arte con otras acerca del lenguaje y la ciencia, como Gerber llegó a hacer en Die Sprache und das Erkennen (El lenguaje y el conocimiento) en $1884^{18}$. Más allá de la dimensión manualística del arte retórico del lenguaje, Nietzsche plantea la cuestión archi-filosófica, incluso analítico-filosófica en términos de Austin (o de Wittgenstein), de cómo hacemos cosas con el lenguaje, y la aún más filosófica cuestión de cómo el lenguaje puede hacer cosas para (o con) el que lo usa ${ }^{19}$. Como ha resaltado el filósofo alemán del lenguaje y del signo, Josef Simon, Nietzsche sitúa su análisis del lenguaje en los completamente familiares términos de discusión acerca de las aserciones válidas e inválidas, planteándolo en el contexto de la posibilidad crítica del conocimiento como tal ${ }^{20}$. Este enfo-

así como de Jean-Luc Nancy, Philippe Lacoue-Labarthe y Jacques Derrida, y muy especialmente en contraste con los Nietzsche Studien en respuesta a Anthonie Meijers y Martin Stingelin y cuya tradición de mutua respuesta a nivel de las lecturas literarias comparadas continua sin cesar.

${ }^{18}$ Véase Gerber, J., Die Sprache und das Erkennen, R. Gaertners Verlagsbuchhandlung, Berlin, 1884.

${ }^{19}$ Tomo la imagen de Heidegger de cómo la filosofía (y el lenguaje) puede hacer cosas con nosotros en otra parte.

${ }^{20}$ Simon, Josef, «Grammatik und Wahrheit: Über das Verhältnis zur metaphysischen Tradition», Nietzsche-Studien, 1, 1972, 1-26 (traducción inglesa: «Grammar and Truth: On Nietzsche's Relationship to the Speculative Sentential Grammar of the Metaphysical Tradition», en Babich, B.E. (ed.), Nietzsche, Theories of Knowledge, and Critical Theory: Nietzsche and Science I, Kluwer, Dordrecht, 1999, pp. 129-151). Además del énfasis dado por este autor a la deuda directa de Nietzsche (contrariamente a las presunciones dominantes de una deuda sólo mediata) con respecto a Kant (vía Schopenahuer o Lange), otros estudiosos, especialmente Alexis Philonenko, Olivier Reboul y Friedrich Kaulbach, han enfatizado la dimensión kantiana del pensamiento nietzscheano, tanto positivamente como por reacción. Para una de los primeros y más extensos ejemplos, véase la clásica perspectiva de Hans Vaihinger, Die Philosophie des Als Ob. System der theoretischen, praktischen und religiösen Fiktionen der Menschheit auf Grund eines idealistischen Positivismus: mit einem Anhang über Kant und Nietzsche, F. Meiner, Leipzig, 1911. Véase también Reboul, Olivier, Nietzsche critique de Kant, Presses Universitaires de France, Paris, 1974; Hamacher, Werner, «Das Versprechen der Auslegung. Überlegungen zum hermeneutischen Imperativ bei Kant und Nietzsche», en Bolz, N. - Hübener, W. (eds.), Spiegel und Gleichnis, Königshausen and Neumann, Würzburg, 1983, pp. 252-387. 
que por parte de Nietzsche ha ofrecido la base textual para estudios analíticos, tales como los ejemplificados por las primeras reflexiones de John Wilcox, así como el estudio académico seguido por el libro de Maudemarie Clark sobre la cuestión de Nietzsche y la verdad.

No obstante, aquellos que han tomado Nietzsche en serio como filósofo se han inclinado más por obviar sus tesis acerca de la verdad y la mentira, y han desatendido sus reflexiones sobre la posibilidad del conocimiento, sin mencionar sus teorías cosmológicas y ecológicas, o sus juicios sobre la calidad de la teoría científica -desde Darwin hasta Boscovich, y desde Demócrito hasta la fisio-psicología de la dieta. En efecto, lo típico de los estudios nietzscheanos -en las dos caras de la conocida división 'analíticos-continentales'- ha sido la atención puesta en el poder de 'invención' de Nietzsche, por el que se le considera no sólo como inventor de una concepción de la vida «como literatura $»^{21}$-por usar la convención promovida por Alexander Nehamas y Michel Foucault-, sino de enteras áreas de estudio, como los 'presocráticos', que fueron supuestamente inventados por Nietzsche ${ }^{22}$, incluyendo la idea -es decir, la constelación dinámica- de que el mismo Dioniso está en el nacimiento de la 'tragedia' ${ }^{23}$. Y asumiendo aquello a lo que parece conducir el razonamiento de los estudiosos -que Nietzsche era capaz de fabricar o 'inventar' perspectivas globales a partir de convenciones ficticias, como la filosofía pre-platónica o la idea de lo dionisíaco-, también puede decirse que él inventó una visión de la verdad, una visión de la ciencia, e incluso una visión de lo que hacen los físicos -descrito, con una término de su propia disciplina, como una 'interpretación', más que como un hecho sobre el mundo (JGB §22). Así cuando Nietzsche anota que «Acaso sean cinco o seis las cabezas en las cuales va abriéndose paso ahora la idea de que también la física no es más que una interpretación y un arreglo del mundo» (JGB §14), calificando cierta metodología científica (simplicidad) de deliberada articulación de la «más grande estupidez posible» ${ }^{24}$, y cuando

${ }^{21}$ Nehamas, Alexander, Nietzsche: Life as Literature.

${ }^{22}$ Borsche, Tilman, «Nietzsches Erfindung der Vorsokratiker», en Simon, Josef (ed.), Nietzsche und die philosophische Tradition, Königshausen \& Neumann, Würzburg, 1985, pp. 62-87. Borsche ofrece una de las ilustraciones de esta convención argumentativa que recientemente ha hallado expresión en los nuevos estudios de Porter (cf. nota más abajo).

${ }^{23}$ Porter, The Invention of Dionysus and Nietzsche and the Philology of the Future.

${ }^{24}$ Extendiendo el principio primordial de la ciencia lo más posible (o de manera completamente deliberada) la estupidez se convierte en una ocupación favorita. Así, Nietzsche escribe que el triunfo de la visión crecientemente mecanicista del proceso del mundo requiere una calculada estupidez y una no pequeña complicidad con nuestros propios supuestos (su tesis puede ser comparada con su comentario acerca de los teólogos de Tübingen que bucean en los arbustos en busca de nuevas 'facultades', cf. JGB §11): «Jedermann kennt diese Prozeduren: man läßt die "Vernunft" und die "Zwecke", so gut es gehen will, aus dem Spiele, man zeigt, daß, bei gehöriger Zeitdauer, Alles aus Allem werden kann, man verbirgt ein schadenfrohes Schmunzlen nicht, wenn wieder einmal die Aanscheinende Absichtlichkeit im Schicksale" einer Pflanze oder eines Eidotters auf Druck und Stoß zurückgeführt ist: kurz, man huldigt von ganzem Herzen, 
llega hasta criticar los 'prejuicios' de la ciencia o la 'tosquedad e ingenuidad' de la convención científica del cálculo (FW §123 y §273), o también cuando Nietzsche desacredita la creencia ilustrada en la oposición entre logos y mito, declarando que «el mito mayor es el mito del conocimiento» ${ }^{25}$, sus declaraciones por lo común no son tomadas como proposiciones filosóficas de las más serias.

Así, en calidad de cierta especie de aclaración de la atmósfera conceptual, recientes tendencias interpretativas tienden cada vez más a sugerir que cualquier cosa hiciera Nietzsche -sea crítica retórica o cultural, o 'terapia', o precisamente mero juego paródico con nuestra propia aproximación demasiado seria (¿o ardiente?) al estudio académico-, no era, no es filosofía. Así se ha argumentado que Nietzsche era hijo de su tiempo -limitado por la termodinámica de sus días o también por las ciencias biológicas y de la salud (supersticiosas y no-ciencia) de su época. A finales de siglo, se comían galletas con salvado y otros cereales para evitar la enfermedad de la que el propio Nietzsche fue afligido infamemente -el sufrimiento por el abuso y su consecuente enervación psicológica-; hoy en día se come salvado (y otras fibras) para evitar otro sufrimiento, los dolores intestinales con los que Nietzsche por su parte estuvo fuertemente aquejado y, como sus contemporáneos observaron, no de manera muy benigna, por buenas razones ${ }^{26}$. Ahora bien, esas pretendidas limitaciones, siempre acríticas, presentan problemas. Pero aquí me interesan menos esas tendencias limitadoras -por lo menos en la medida en que resultan inevitables en el proyecto de la historia de las ideas-, que las consecuencias de ese estudio histórico (a recuperar) para una posible comprensión de la relevancia de la perspectiva filosófica de Nietzsche con respecto a la filosofía de las ciencias de hoy en día, y por tanto, ceteris paribus, con respecto a nuestra comprensión actual de la ciencia. Aquí lo que está en cuestión es el corolario que se deriva tan a menudo de esas reflexiones

wenn in einer so ernsten Angelegenheit ein scherzhafter Ausdruck erlaubt ist, dem Principe der größtmöglichen Dummheit» KSA XI 36[34]. Véase también SE §6.

${ }^{25}$ Así, Nietzsche declara de modo característico: «Die größte Fabelei ist die von Erkenntniß» KSA XIII 141. Véase FW \$373, «La 'ciencia' como prejuicio».

${ }^{26}$ Aunque ofrecido explícitamente por medio de un examen del contexto histórico, en la lectura del tema «Nietzsche y la biología de su tiempo», más allá del darwinismo (mucho más literario y social que ecológico-evolucionista o biológico) que constituye la primera parte de la monografía de Gregory Moore, Nietzsche, Biology, and Metaphor (Cambridge University Press, Cambridge, 2001), este estudioso cae inevitablemente en esta tendencia actualizadora. Resulta particularmente revelador, pero también de los supuestos del mismo autor, que son los supuestos actuales con respecto a la dieta y a la salud, es la discusión de la segunda parte sobre la degeneración. Cf. también en esta nueva línea de lo que podría llamarse una 'Nordau-renaissance', Stone, Dan, Breeding Superman: Nietzsche, Race and Eugenics in Edwardian and Literary Britain (Liverpool University Press, Liverpool, 2002), así como el informado y equilibrado capítulo sobre Nietzsche de Marc A. Wiener, «Laws of Degeneration», en Wagner and the AntiSemitic Imagination (University of Nebraska Press, Lincoln, 1995); y también Janz, y para una panorámica amena, Allison, D.B., op. cit. 
restrictivas, de que esto afecta, en un sentido más general, a la representación de Nietzsche 'como' filósofo en cualquier sentido del término. La tesis implícita y explícita aquí es que no necesitamos, dado nuestro conocimiento avanzado actual -sea nuestro conocimiento de la filosofía, de la ciencia, de la historia, de la filología clásica, de la literatura-, tomar a Nietzsche literalmente acerca de todas las cosas -particularmente cuando él estiliza lo que dice como lo hace. Por tanto, los filósofos (analíticos), los estudiosos de los clásicos y demás, no deben preocuparse. Aun cuando Nietzsche parece hablar de filosofía -de los clásicos, de estética, historia, ciencia, etc.-, nosotros no debemos considerarlo literalmente: él sólo está bromeando (experimentando) con las ideas -no está reivindicando el manto de estudioso académico. Esta un tanto 'deflacionaria' (o analítica $)^{27}$ tendencia interpretativa es característica, en especial, de los estudios actuales sobre la 'retórica' y el estilo de Nietzsche (aunque seguramente, por una parte, las concepciones contemporáneas de la retórica, y por otra la formación especializada personal de Nietzsche en la tradición clásica de la retórica de los antiguos griegos y romanos, implican de manera significativa diferentes arenas) ${ }^{28}$. En contraste con estas recientes e influyentes tendencias,

\footnotetext{
${ }^{27}$ Esta característica tiende a marcar a las aproximaciones a Nietzsche llamadas analíticas. Véase para referencias y una discusión más amplia, Babich, B.E., «On the Analytic-Continental Divide in Philosophy: Nietzsche's Lying Truth, Heidegger's Speaking Language, and Philosophy», en Prado, C.G. (ed.), A Dubious Estrangement: Analytic and Continental Philosophy, Humanity Books, Amherst (NY), 2003.

${ }^{28} \mathrm{Me}$ refiero a una importante pero potencialmente problemática (por demasiado literal y demasiado reductora a la letra) nueva tradición investigadora en los estudios nietzscheanos, consistente en la investigación de las fuentes y en la indagación de atribuciones, tradición orientada hacia la generación de una enciclopedia, un diccionario o un manual, algo evidente todo a lo largo del conjunto de la investigaciones académicas. Acerca de la inspiración original de la otra tendencia, algo ahistórica, a leer a Nietzsche como el iniciador de un giro retórico o como el descubridor de la retórica, tras su llegada a Basilea, cf. Lacoue-Labarthe, Philippe, «Le détour (Nietzsche et la rhétorique)», Poétique, 5, 1971, 53-76. Véase también Lacoue-Labarthe, Philippe - Nancy, JeanLuc, «Friedrich Nietzsche: Rhétorique et langage. Textes traduits, présentés et annotés», Poétique, 5, 1971, 99-142; y Man, Paul de, «Nietzsche's Theory of Rhetoric», Symposium: A Quarterly Journal in Modern Foreign Languages, 1974, 33-51 y «Rhetoric of Tropes (Nietzsche)», en Allegories of Reading: Figural Language in Rousseau, Nietzsche, Rilke, Freud, Yale University Press, New Haven, 1976. Para un resumen y un enfoque más conservador, cf. Behler, Ernst, «Nietzsche's Study of Greek Rhetoric», Research in Phenomenology, 25, 1995, 3-26. En muchos y algunas veces incendiarios casos, contestando a menudo las expectativas acerca de la modernidad innovadora de Nietzsche, recientes estudios detallan las fuentes comunes de las que Nietzsche extrajo las ideas que se supone que 'inventó'. Esta investigación de las fuentes justifica cada vez más el carácter derivado de esas mismas ideas. Aunque esta misma tendencia (reminiscencias del modo de Georg Stack de remontar los conceptos de Nietzsche a una fuente en Emerson o en Lange) se corresponde de manera alarmante con el fracaso de la metodología clásica que una vez Nietzsche diagnosticó contra su propia disciplina de la filología clásica (lo que llamó provocadoramente una 'carencia' de filología), la misma convención se ha hecho cada vez más dominante en la estela de la importante contribución de Meijers y Stingelin «Konkordanz zu den wörtlichen Abschriften und Übernahmen von Beispielen und Zitaten aus Gustav Gerber: Die
} 
continuo argumentando más abajo, y a lo largo de todo el apartado siguiente, que precisamente a través del estilo de Nietzsche -es decir, por medio de lo que Nietzsche puede 'hacer' con las palabras- Nietzsche arriesga formular una tesis muy especial y hasta la fecha todavía muy raramente asumida, y no obstante justamente filosófica.

\section{El SONIDO Lírico DE LA TRAGEDIA: Música GRIEGA Y PALABRAS GRIEGAS}

Nietzsche enseñaba a sus estudiantes en Basilea que una genuina comprensión clásica del arte de la retórica (o del estilo) incluye un examen del significado y del funcionamiento de la metáfora, de la metonimia y de todos los tropos del lenguaje. Es un lenguaje escrito precisamente para un público dado o específico, pero nunca para un público general, y esto último no por algún tono principalmente antidemocrático predominante en la antigüedad, sino porque ningún libro puede ser escrito para un público general sin que al mismo tiempo y de manera inherente no esté dirigido a alguien. Podemos hallar otra expresión de esta intrínseca limitación estilística de los textos especializados o esotéricos, en el hecho de que el problema de la filosofía clásica es el contexto específico global en el que se desarrolla. Como no sólo Pierre Hadot, sino también Foucault, Ricoeur y Gadamer, y como sin duda Ivan Illich nos han recordado de manera diversa y completa -si no lo habíamos aprendido ya de Nietzsche-, la filosofía, que originariamente era una forma de vida, no es en absoluto un libro abierto. Más bien, su especial forma dialógica, sus confesiones y meditaciones, son, en un sentido completamente literal, prácticas deliberadas de un tipo muy particular. Además, estas prácticas, que no forman parte del texto en sí mismo -aunque sí están trazadas en el texto mismo-, se han perdido en gran parte para nosotros, quienes no sabemos o no podemos conocer cómo entender o, como Nietzsche diría, quienes no sabemos cómo escuchar lo que leemos. Esto es lo que Nietzsche quiere decir al principio de Así habló Zaratustra, donde él hace tronar en boca de Zaratustra: «Allí están ellos (dijo a su corazón), allí se ríen: ellos no me entienden, yo no soy la boca para estos oídos. ¿No debe uno hacer añicos sus oídos primero para enseñarles a oír con sus ojos?» ${ }^{29}$. Y cuando nos

Sprache als Kunst (Bromberg, 1871) in Nietzsches Rhetorik-Vorlesungen und in Über Wahrheit und Lüge im außermoralischen Sinne», Nietzsche-Studien, 19, 1988, 350-368, y de los ensayos interpretativos que la acompañan Stingelin, «Nietzsches Wortspiel als Reflexion auf poet(olog)ische Verfahren», Nietzsche-Studien, 19, 1988, 336-249; y Meijers, «Gustav Gerber und Friedrich Nietzsche. Zum historischen Hintergrund der sprachphilosophischen Auffassungen des frühen Nietzsche», Nietzsche-Studien, 19, 1988, 369-390. Véase para más información Kopperschmidt, Joseph - Schanze, Helmut, Nietzsche oder 'Die Sprache ist Rhetorik', Fink, Munich, 1994.

${ }^{29} \mathrm{Za}$ Vorrede §5. Nietzsche nos ofrece aquí una inversión de la referencia de Aristóteles al uso de metáforas proporcionales, en su Rhetorica, para ayudar a que nuestros oyentes 'vean', cf. Rhetorica, lib. III, 10-11. 
damos cuenta de su estilo, nos parece una licencia arbitraria el ignorar lo que él dice de esa manera tan característica.

Los estudiosos han leído de esta manera el lenguaje nietzscheano de sonidos tan rompedores, y lo han hecho oyéndolo con los ojos, como pura charla figurativa, mera metáfora, como conversando con nuestro corazón. Pero como resaltó Gustav Gerber -el teórico del lenguaje mencionado más arriba como la influencia sobre las reflexiones nietzscheanas acerca de la verdad y de la mentira- en su estudio El arte del lenguaje, y como la más amplia tradición canónica de la retórica -antes de Gerber- había ya enseñado a Nietzsche, la metáfora imbuye al lenguaje por todas partes. Tomar cualquier declaración en sentido literal, tomar la palabra por la cosa, es exigir más de lo que da el lenguaje.

Más allá del arte del lenguaje, más allá de la pura metaforicidad, el desafío de Nietzsche a nuestros oídos, exigiendo que escuchemos el texto, recuerda sus primeras y más duraderas directrices como filólogo. Para esta tarea, así argumentó el joven Nietzsche en su primer libro, el texto del pasado es la llave. Las marcas escritas conservadas del pasado, que son arqueológicas en cualquier sentido vulgar del término, son la concretización de un modo de vida desaparecido. En el caso de los escritos de los antiguos griegos -que usaban un alfabeto expresado fonéticamente y un lenguaje hecho de metro y ritmo-, así lo argumentaría Nietzsche, nos hallamos enfrentados a auténticas 'grabaciones', a un helado pero todavía a penas descifrable o legible depósito de sonidos perdidos. Nietzsche argumentaría que nosotros no oímos la música de la antigua tragedia, y por la misma razón sólo tenemos la parte más desnuda de lo que necesitaríamos para entender la antigua tragedia griega. No obstante, concluiría con su sugerente idea de que no carecemos de toda pista de este arte, pues si lo consideramos desde sus orígenes en la canción popular, y sólo si hacemos esto, el espíritu de la música puede ser oído (no meramente leído) en la poesía lírica.

Lo que Nietzsche encontró, cuando intentaba describirla en El nacimiento de la tragedia a partir del espíritu de la música, así como en sus primeras conferencias públicas, no fue más que la clave de la tragedia antigua en la canción popular. Nietzsche describe esta clave como la voz del pueblo que debe ser oída en la poesía lírica, una vez que haya sido distinguida de la completamente moderna aproximación literaria como expresión subjetiva. Así, la oposición entre Homero y Arquíloco ${ }^{30}$, representada como la oposición entre la poesía épica y la lírica, proporciona el eslabón perdido con la tragedia interpretada como 'drama musical' de la antigua Grecia. Con este contraste poético, Nietzsche afirma que ha «indicado la única posible relación entre la poesía y la música, entre palabra y tono» (GT §6). La partitura de esta música tiene que ser oída en la poesía, como una expresión de la música de la palabra escrita. En su

\footnotetext{
${ }^{30}$ El reciente enfoque sobre el elemento agonístico en Nietzsche ha desgraciadamente oscurecido este importante aspecto en Nietzsche, al valorizar el agôn como práctica política.
} 
primera conferencia en Basilea, «El drama musical griego» (KSA I 515) -una conferencia leída privadamente a Richard Wagner en el verano 1870-Nietzsche sostuvo, recurriendo a la filología, que es posible descubrir el ritmo musical del pasado, y así literalmente 'oír' con nuestros ojos. Finalmente, Nietzsche tomó su inspiración para la comprensión del drama musical griego -tal como más tarde intentaría comprender El nacimiento de la tragedia-fuera del propio texto -la filología es el único medio arqueológico para esta indagación-, pero sólo la encontró leyendo musicalmente, es decir, atendiendo a la música del texto (GT §17). Nótese que esta temprana y duradera visión no tiene nada que ver, por emplear la expresión que Nietzsche emplearía a tal efecto en su Nietzsche contra Wagner -y en general contra el general filisteísmo cultural-, con confundir el libreto con la ópera, o - usando la oposición preferida por Wagner-, con subordinar la música a la obra de arte total, tal como Wagner mismo concebía la música, como sólo una parte del todo ${ }^{31}$. Más bien, es en razón de que en el caso literario de la antigüedad no tenemos nada más que el texto, la falta de música -y la ausencia concomitante de una lectura musical en el sentido de Nietzsche- no legitima la conclusión de que lo que nos falta hoy en día sería por tanto la 'partitura' - de lo que están convencidos tantos estudiosos de la antigüedad $^{32}$. La reivindicación radical de Nietzsche (todavía hoy) es que el texto mismo era la propia música ${ }^{33}$. La tragedia había surgido de la canción

${ }^{31}$ Cf. Campbell, Moody, «Nietzsche-Wagner to January, 1872», PMLA, 56, 1941, 544-577; pero véase también Ruckser, Udo, «Zum Fall Wagner-Nietzsche», Allgemeine Musik-Zeitung, 11, 1913, 1481-82. Agradezco a Holger Schmid por haber llamado mi atención (además de los artículos citados) provocativamente sobre los diversos aspectos de esta temática.

${ }^{32}$ Cf. Mathiesen, Thomas J., Apollo's Lyre: Greek Music and Music Theory in Antiquity and the Middle Ages, University of Nebraska Press, Lincoln, 1999. Hay que resaltar que Nietzsche pone mucho cuidado en distanciarse de los enfoques medievales en su conferencia de Basilea «El drama musical griego». Incluso el extraordinariamente cuidadoso M.L. West no hace ninguna observación sobre la exagerada atención dada a la relativamente escasa evidencia de notación musical (West, M.L., Ancient Greek Music, Clarendon, Oxford, 1992, donde la evidencia de notación es enumerada como la última fuente de las cinco fudamentales para la comprensión de la antigua música griega, y que entonces es tratada al detalle). West cita a Bellermann, J.F., Die Tonleitern und Musiknoten der Griechen, Berlin, 1847, así como a Sachs, Curt, «Die griechische Instrumentalnotenschrift» y «Die griechische Gesangsnotenschrift», Zeitschrift für Musikwissenschaft, 6, 1923-1924, 289-301 y 7, 1924-1925, 1-5; pero a parte de Bellermann no cita otras monografías recientes. Véase también Rossbach, A. - Westphal, R., Theorie der musischen Künste der Hellenen, Leipzig, 1886. Aunque Warren D. Anderson en su apéndice sobre «Saclae Systems and Notations», incluido en Music and Musicians in Ancient Greece (Cornell University Press, Ithaca, 1994) resalta acertadamente el estudio de West como extraordinario, también hace observar el peligro de generar demasiada teoría (y demasiado aparato de notación musical) sobre la base de tan pocas evidencias: antes de los Elementa harmonica de Aristoxeno (nacido en el 360 a.C.), no tenemos constancia de ningún sistema de tonoi: en «distintos grados la misma laguna de conocimiento caracteriza nuestro tratamiento de las harmoniai y el sistema de escalas generalmente durante el período clásico» ibid., p. 202. Y Anderson anota que «no tenemos rastro alguno de un sistema de notación musical griega que 
popular y en sentido completamente literal había nacido a partir de la música, de manera que la tragedia está imbuida completamente de música ${ }^{34}$, y nacida y desarrollada así, habría sido como resultado de la pérdida del mismo espíritu musical que el drama musico-trágico sufriría su muerte a manos de sí mismo. Este 'subtexto' -la muerte de la forma de arte trágica-fue el argumento explícito de El nacimiento de la tragedia ${ }^{35}$. Si los intérpretes continúan revelando esta última paradoja con alguna sorpresa, Nietzsche presenta de manera igualmente explícita la clave de su explicación de la decadencia de la tragedia en términos de su génesis original: «de qué modo la tragedia, así como únicamente puede nacer del espíritu de la música, así también perece por la desaparición de ese espíritu» ${ }^{36}$.

Dada la desaparición del espíritu de la música trágica, tal como Nietzsche elaboró esta idea en El nacimiento de la tragedia más adelante, cuando nosotros hoy leemos los textos de la tragedia antigua, nosotros vemos pero no oímos con nuestros ojos ${ }^{37}$. Esto puede ser aclarado comparándolo con la diferencia que se da entre un músico que lee una partitura musical y un no-músico que lee la misma partitura. Meramente leyendo la partitura, el lector preparado musical-

pueda ser datado con seguridad como muy pronto en el siglo quinto». Lo que tenemos son los símbolos grabados por Alipio, «quien nos provee de los únicos medios o intentos para entender las melodías de la antigua Grecia» ibid., p. 203. Como se suele admitir que Alipio vivió no antes del cuarto siglo d.C., Anderson concede que «habría sido un milagro que él hubiera tenido éxito en conservar la práctica musical del período clásico, seis o siete siglos antes de su época». Por ello, aunque con bastante simpatía, Anderson cita la controversia de Reithmüller de que «por muy complejas y sutiles que sean, la impresión más fuerte es que con lo que tratamos aquí es con cierto tipo de creación de documentos» ibid., p. 202, donde se cita la monografía Riethmüller, Albrecht - Zaminer, Frider (eds.), Die Musik des Altertums: Neues Handbuch der Musikwissenschaft, ed. C. Dahlhaus, Laaber-Verlag, Laaber, 1989, vol. I.

33 «Wer heutzutage von Aeschylus Sophocles Euripides spricht oder hört, der denkt unwillkürlich zunächst an sie als Litteraturpoeten, weil er sie aus dem Buche, im Original oder in der Übersetzung hat kennen lernen: dies ist aber ungefähr so als ob jemand vom Tannhäuser spricht und dabei das Textbuch und nichts mehr meint und versteht. Von jenen Männern soll also gesprochen werden, nicht als Librettisten: sondern als Operncomponisten» KSA VII 9.

34 «El entero arte de la poesía y de la música ha nacido de la canción popular» KSA I 529.

35 «Die griechische Tragödie ist anders zu Grunde gegangen als sämmtliche ältere schwesterliche Kunstgattungen: sie starb durch Selbstmord, in Folge eines unlösbaren Conflictes, also tragisch» GT $\$ 11$ (KSA I 75).

${ }^{36}$ «wie die Tragödie an dem Entschwinden des Geistes der Musik eben so gewiss zu Grunde geht, wie sie aus diesem Geiste allein geboren werden kann» GT §16 (KSA I 102).

${ }^{37}$ Nietzsche expone la comparación con la Edad Media, en esa época cuando llega un punto en que gusto y convención cayeron en una disparidad tan grande que ya no se podía, a causa de las convenciones deseables, componer música para los oídos, sino sólo para los ojos. El resultado fueron literalmente partituras 'ilustradas', hasta llegar al extremo absurdo de escribir «las notas con algún color: como el verde en el caso de de las plantas y el púrpura para los viñedos» KSA I 517. Con respecto a los textos hablados del drama musical antiguo, nosotros, igual que los escoliastas medievales tan absortos por el color, estamos encerrados entre los signos que escudriñamos, en vez de oír con nuestros ojos. 
mente oye lo que el otro sólo ve. Justo en este grado y por esta misma razón, Nietzsche declara «Estamos condenados al malentendimiento con respecto a Píndaro, Esquilo y Sófocles» (KSA I 517). Y como nosotros no podemos 'leer viendo' la tragedia antigua, porque nosotros literalmente no sabemos 'oir' con nuestro ojos, nosotros quedamos reducidos a mundos de silencio apartados de cualquier comprensión de la tragedia antigua. Somos mundos alejados no sólo porque la tragedia antigua era representada al aire libre de día -no en los teatros oscurecidos de hoy-, o porque faltase el factor sorpresa de una nueva trama, sino porque su música no suena ya para nosotros ${ }^{38}$. Como nos ocupamos sólo, en el mejor de los casos, del papel del actor o del público -piénsese en los infinito debates ad nauseam, acerca del protocolo de que el público se acerque o no la escena, lo que haría de él un buen o mal público-, nosotros no podemos más que interpretar mal la centralidad meditativa del coro como vehículo de la obra en su totalidad. Esta misma música perdida es también la clave de la esencia de la tragedia antigua tal como se muestra, no en el drama, sino en términos de pathos, tal como entiende Nietzsche el término en este contexto, como un sentimiento enteramente musical.

De esta manera, el estudio que hace Nietzsche de la tragedia se opone a Aristóteles en dos puntos: rechazando el mito del mito (es decir, la trama), y rechazando la función de anagnōrisis, como respuesta catártica por parte del público o como su beneficio edificante. En lugar de 'terapia' del teatro, Nietzsche declara el misterio de la disonancia musical como la clave de la esencia de la tragedia. Para una comprensión del drama musical griego, así como para una aproximación al nacimiento de la tragedia, Nietzsche se vuelve hacia los restos preservados en las palabras, que permanecen como evidencias de lo trágico -a través de la poesía lírica. Y no hay que sorprenderse si las herramientas filológicas usadas por Nietzsche para explorar la antigüedad son las mismas que utiliza para cualquier problema. Si en sus primeros escritos utiliza las herramientas de la filología -herramientas de estilo y de lectura- para dilucidar el problema del artista lírico, es decir, el problema del poema como sonido cristalizado o como legado musical, sus últimos escritos se centran igualmente en las mismas herramientas, es decir, en las palabras, en la forma de una genealogía de las valoraciones terminológicas para producir diferentes efectos. Así podemos hallar un paralelo a su discusión sobre el poeta lírico en El nacimiento de la tragedia, en el análisis sobre 'lo noble' -o la 'bestia rubia', o también el 'esclavo'-, en La genealogía de la moral. Porque esta 'genealogía' es precisamente lo que Nietzsche dice que es, cuando titula el libro como un ensayo de un tipo retórico muy específico: una polémica. Más que una recuperación de supuestos hechos históricos -nunca ha habido tal edad antigua-, más que la expresión de

\footnotetext{
${ }^{38}$ «Somos incompetentes con respecto a la tragedia griega porque su influencia mayor descansó en alto grado en un elemento que se nos ha perdido, la música» KSA I 529.
} 
las propias fantasías y deseos de Nietzsche, su 'polémica' sobre el origen de la moralidad lo que hace, como él mismo nos dice literalmente, es desarrollar las últimas consecuencias de un análisis etimológico. Nietzsche afirma en el cuarto apartado del primer tratado: «El indicio del camino correcto fue para mí la cuestión de cuál es la auténtica significación etimológica de la designación 'bueno' acuñada en los distintos lenguajes» (GM I §4). Justamente por esta razón, Nietzsche titula sus iniciales reflexiones en La genealogía de la moral recurriendo al contraste entre parejas de términos, subrayando la herencia o la fortuna lingüística de lo que llamamos 'bien': recordemos, 'bueno y malo', 'bueno y malvado' ${ }^{39}$.

Las mismas consideraciones que llevaron a Nietzsche a sus planteamientos musicales (apolíneo-dionisíaco) en El nacimiento de la tragedia-oponiéndose a una interpretación acentuadamente epistémica (aristotélica) del beneficio catártico de la pura disonancia (drama trágico o musical)- dieron como consecuencia que inevitablemente, como parece, su libro haya carecido de una influencia general $^{40}$. Pero la idea de que los textos esotéricos resultan ser exotéricamente inaccesibles, la repite Nietzsche una y otra vez, y todavía podría dejarse pasar si no fuera por las complicaciones que acarrea, pues invierte el significado ordinario tanto de los supuestos clásicos como de los supuestos positivistas del pensamiento científico y lógico moderno.

\section{TEXTOS CLÁSICOS: LA TRADICIÓN DE LOS FILÓSOFOS Y LOS REYES DEL FUTURO}

En cuanto 'educador' escribiendo para su lector, Nietzsche elabora una y otra vez los límites de la direccionalidad retórica del escrito, bajo la forma de la cuestión de la lectura y de la necesidad respectiva de aprender a leer. Esta tarea ejemplar la desarrolla hasta llegar a Así habló Zaratustra. Un libro para todos y para nadie, así como en el Crepúsculo de los ídolos, Ecce homo e incluso en el (incompleto) Anticristo. Este proyecto didáctico de escritura era expresa y explícitamente exotérico, relacionado con la preocupación de comunicar en general. Por el contrario, el problema esotérico o interno de la filología sería el de la reciprocidad entre la manera de escribir y la manera de leer: el problema de los buenos lectores. Para Nietzsche, siempre arcaico en su sensibilidad, lo semejante requería ser conocido (o por lo menos empezar a ser reconocido) por lo semejante. Y para los filólogos académicos, Nietzsche remarca en una nota en La gaya ciencia que el proyecto

\footnotetext{
${ }^{39}$ La significación de Nietzsche para el libro de MacIntyre, Alasdair, After Virtue (Univ. of Notre Dame Press, Notre Dame, 1972) resulta obvia en esta cuestión.

${ }^{40}$ En contraste con los libros y tratados influyentes (Nietzsche está pensando en particular en el Nuevo Testamento, y veremos más abajo cuán importante fue este ideal paradigmático de influencia para Nietzsche) «todo libro puramente científico está condenado a vivir una existencia humilde entre humildes, y a ser crucificado al final para nunca resurgir» VM $§ 98$.
} 
disciplinar de la filología, como empresa de conservación de los 'grandes' libros -sin tratar de la discutida denominación actual como tales-, presupone lo que Nietzsche confirma ser la última profesión de fe del filólogo. Esta es la convicción de que «no haya carencia de esos raros seres humanos (aunque no se les vea) que saben utilizar realmente estos libros tan preciados - precisamente aquellos que escribirían, o podrían escribir, libros del mismo tipo». Y usando un tropo diestramente enfático, repite su requisito: «Pienso que la filología presupone una noble fe - la de que, en vista a aquellos pocos nobles seres humanos, que están siempre 'por venir' pero que nunca llegan, una suma verdaderamente amplísima de trabajo fastidioso e incluso sucio tiene que ser hecha antes: todo él es trabajo in usum Delphinorum» (FW §102, cursiva mía).

Merece la pena observar la relevancia de esta alusión in usum Delphinorum, mucho más allá de las limitaciones de clarificación proporcionadas por el moderno estudioso filólogo, especialista en Schlegel y traductor de Nietzsche, Walter Kaufmann. La fuerte relevancia, bajo el punto de vista de la filología clásica, de la invocación de esta frase por parte de Nietzsche -una variante de ad usum Delphini- ha sido a menudo trivializada, tal como lo hace inevitablemente el comentario de Kaufmann -o en todo caso, por parte de muchos estudiosos, es pasada por alto. Hace alusión al paternalista proyecto perfecto, por ser imperial, de crear una edición especial de textos clásicos griegos y romanos, destinados «al uso del Delfín», es decir, al hijo de Luis XIV ${ }^{41}$. Lo importante aquí, pues esta era la idea de Nietzsche al insertar esta invocación en su propio texto justo en ese punto, es que el estímulo práctico y el carácter cultural del gremio de la filología clásica siguen estando endeudados con este solícito proyecto, y esta misma preocupación, a la vez infinitamente respetuosa e infinitamente diferida, anima el alto tono moral que suele imaginarse perteneciente a los 'grandes libros'. La conexión 'política' entre esta convención filológica estándar y la lectura que hace Nietzsche de Maquiavelo o de Rousseau, no ha sido explorada, según mis conocimientos, por aquellos que discuten a Nietzsche en este contexto.

El problema de Nietzsche aquí reside en que todo el interés del proyecto de la disciplina de la filología es generar un material de fuentes 'arreglado', emprendido con vistas a un lector muy valorado y noble, pero un lector que necesita, en el sentido en que lo necesitaba el Delfín, ser protegido de los aspectos mancillantes

${ }^{41}$ Cf. Huet, P.D. (ed.), Collection de classiques latins «Ad usum Delphini» (1674-1691), 67 volumes, dont 39 auteurs, 5 dictionnaires, así como Saint-Pierre, Puget de, Histoire de Charles de Sainte-Maure, duc de Montausier, Guillot, Genève-Paris, 1784). Cf. también Bossuet, J. de, Politique tirée des propres paroles de l'Ecriture sainte, P. Cot, Paris, 1709 ; y Cordemoy, Géraud de, «De la nécessité de l'histoire, de son usage \& de la manière dont il faut mêler les autres sciences, en la faisant lire à un prince», en Divers traités de métaphysique, d'histoire et de politique, Paris, 1691. Podemos encontrar ejemplos del proyecto en Doujat, Jean, Abrégé de l'histoire romaine et grecque, en partie traduit de Velleius Paterculus, et en partie tiré des meilleurs auteurs de l'Antiquité, Paris, 1671; y Fléchier, Esprit, Histoire de Théodose le Grand, S. MabreCramoisy, Paris, 1679. 
-cuestionables, desencaminados, erróneos- de este material verdaderamente fuente. Considerándolo con toda la interna presuposición esotérica, propia del miembro reconocido del gremio filológico, el 'Delfín' debería ser entendido como correspondiente a los estudiosos por venir, vulnerables y preciados 'lectores futuros', que necesitan ser protegidos de los aspectos menos edificantes de la literatura clásica. A Nietzsche le gustaban las metáforas pictóricas de la restauración y comparaba el arte del filólogo con el trabajo de restauración de pinturas dañadas. Pero lo que no olvida -lo que los filólogos actuales parecen no haber captado todavía enteramente y lo que aquellos que bajo el pretexto de la historia continúan como filólogos parecen no haber captado en absoluto, ignorando lo que Nietzsche llamaba sensibilidad histórica hacia el devenir ${ }^{42}$ - es que los 'textos' generados en este proceso nunca llegan a ser las obras originales. Ellos son y siguen siendo restauraciones vestidas o convencionalizadas: textos literalmente preparados -y en el proceso expurgados o limpiados- y producidos industriosamente para ojos muy particulares. Si bien ya no tenemos la justificación o el imperativo moral para un proyecto de ese tipo -hoy en día ya no hay delfines y los actuales reyes de Francia, o no existen, o no son honorados como tales- los resultados se mantienen vivos en los métodos de la filología clásica actual, y es una buena referencia de lo que sigue contando como estudio académico de fuentes en el propio caso de Nietzsche ${ }^{43}$.

Dados los presupuestos de sus asunciones filológicas, cuando reivindica sus obras como libros escritos 'para el futuro', Nietzsche no ofrece a la época actual una carta de amor personal, sino una trabajosa rumiadura sobre la condena del autor y el desarrollo del trabajo del filólogo como algo absolutamente vano. En otras palabras, Nietzsche escribe con la esperanza puesta en «aquellos que siempre 'vendrán' pero que nunca están ahí». Piensa que los lectores ideales y mejores están siempre en el futuro, y además que los presupuestos de la disciplina exige esta convicción, a pesar del terco hecho de que no existe instancia alguna para tales lectores ${ }^{44}$. Pero ¿qué escritor no escribe para tales lectores ideales, por

${ }^{42}$ Cf. Osborne, Catherine, Rethinking Early Greek Philosophy: Hippolytus of Rome and the Presocratics, Cornell Univ. Press, Ithaca, 1987. El estudio de Osborne parece haber tenido poca repercusión y poca resonancia en la prensa especializada, y ella misma parece que en el ínterin ha pasado a estudiar otros temas.

${ }^{43}$ La ejemplificación más extrema de Nietzsche de esta representación manufacturada o idealizada de la antigüedad es evidente en el procedimiento de citaciones que emplea en su $\mathrm{La}$ filosofía en la época trágica de los griegos, con sus notoriamente creativas variaciones en el recoger los fragmentos pre-platónicos. Más allá de los movimientos reaccionarios de un Allen Bloom, o del movimiento contra-reaccionario de los actuales etno-clasicistas, que estudian los clásicos de manera antifilológica, para una consideración de las implicaciones más sobrias de este proyecto para la rama de la filosofía más dependiente de la filología, la filosofía antigua, cf. de nuevo Osborne, C., op. cit.

${ }^{44}$ Recuérdese a la compungida Alicia de Lewis Carroll, ese fantasioso portavoz, igual que el Molly Bloom de Joyce, de la lujuria masculina. «Siempre es así» dice Alicia a la Reina de Espadas, «comer ayer y comer mañana, pero nunca comer hoy».

Estudios Nietzsche, 4 (2004), ISSN: 1578-6676, pp. 11-35 
muy imaginarios que puedan ser, y qué escritor no deja de reconocer su ausencia? Ciertamente no Hölderlin, quien escribe con una pasión que sólo la voz de un poeta podría expresar: «iAh, amigo mío, hemos venido demasiado tarde!» ${ }^{45}$.

Como la del filólogo, la esperanza del escritor resultará ser, para Nietzsche, una cuestión de vanidad: vana en más de un sentido. Así mira Nietzsche retrospectivamente a sus propios escritos en Ecce homo, declarando: «Mi tiempo todavía no ha llegado, algunos hemos nacido póstumos» (EH III §1). La reflexión de Nietzsche en este contexto es consistente hasta el punto de producir una 'autolaceración'. Habría sido equivocado, auto-contradictorio, esperar que sus obras fuesen entendidas. Que sus lectores tengan oídos -aquí recurre a la metáfora de tener manos- para sus escritos es una expectativa que iría en contra del requisito constitutivo necesario para entender un libro completamente o en una primera aproximación -o también, pero es algo diferente, un autor-, como precondición interpretativa cuya importancia e indispensabilidad él ha presupuesto siempre.

\section{Leyendo A LOS NUEVOS LeCTORES DE NiETZSCHE: PROYECCIÓN, INVENCIÓN Y RESONANCIA}

Recordando el llamamiento popular, que se producía en una reseña a Más allá del bien y del mal por parte de Josef Widman, calificándolo de «el libro más peligroso de Nietzsche ${ }^{46}$-y equiparando la atracción de Nietzsche hacia la idea de peligro, con una apelación personal-, Nietzsche, en un aparente aprobación de la diagnosis hecha por la lectura de Widmann, respecto a la sensibilidades contemporáneas, añade la advertencia: «En el fondo, nadie puede extraer de las cosas, incluidos los libros, más de lo que ya conoce» (EH III §1). Así Nietzsche medita que si un autor -y claro, es a sí mismo a quien tiene en mente- «habla de sucesos que se sitúan fuera de la posibilidad de la experiencia general o incluso de experiencias especiales», el resultado es necesariamente que lo que uno piensa, una novela o una nueva comunicación, o mejor, -y 'dinamita' es la ambigua metáfora que elige precisamente por su ambivalencia- lo que es dicho, es efectivamente lo que no puede ser oído, produciendo «la ilusión acústica de que donde no se oye nada no hay nada». Nietzsche entonces llega a denunciar precisamente las populares lecturas de su obra, en cuanto lecturas hechas a la imagen del lector: «Quienquiera que crea haber entendido algo de mí, ha revestido algo de mí según su propia imagen ${ }^{47}$.

${ }^{45}$ «Aber Freund! wir kommen zu spät» Hölderlin, Friedrich, «Brot und Wein».

${ }^{46}$ La reseña de Josef Widmann a Más allá del bien y del mal ha sido traducida al inglés en Fauvel, Lysanne - Hyde, Tim, New Nietzsche Studies, VI 1/2, 2000, 195-200.

${ }^{47}$ Sigue a continuación un impaciente catálogo de tales imaginarias lecturas: tomando su obra por una suerte de idealismo, ensayando planteamientos domesticados del Übermensch, o invirtiendo a Zaratustra, o sospechando a Nietzsche de darwinista, o incluso de propagandista del «culto del héroe» de Carlyle. 
En este mismo contexto, la presunta carencia de respuesta a los escritos nietzscheanos, en su época, normalmente se exagera: nos limitamos a repetir la propia visión de Nietzsche en la cuestión de cuán influyente era él. Esto no significa que Nietzsche fuera un best-seller en su época (aunque seguramente sí lo es hoy en día), sino que todas esas reacciones -sea la reseña de Widmann como 'dinamita', o bien la positiva recepción de los escritos nietzscheanos por el académico danés Georg Brandes, o la jocosa mitologización privada, por parte de Nietzsche, de lo que él había percibido que era la recepción de Heinrich Stein- se quedaron cortas ante su ideal. Para Nietzsche la ambición requería una medida muy particular de influencia; el quería lectores muy especiales; quería ser leído de una manera especial. A este respecto no es casualidad que el punto de referencia de Nietzsche fuese la Biblia misma, en cuanto que la analizaba como un parangón estilístico para el tipo de influencia que él se había propuesto para sí mismo como autor. De este tipo de éxito ofrece en el Zaratustra una ejemplificación cómica y paródica, hasta el punto que más tarde describiría esta ambición no menos que «partir la humanidad en dos». Pero lo importante aquí es que Nietzsche no sólo tiene unos criterios muy altos para lo que puede contar como 'influencia', sino también, correspondientemente, unas ideas perspicaces sobre lo que se requiere para conseguirla. En Humano, demasiado humano, refiriéndose al Nuevo Testamento ${ }^{48}$, sin aludir a Dios -o a su famosa muerte-, sino remarcando el acabamiento estilístico consumado del texto, Nietzsche resalta que un hombre perspicaz puede aprender de él todo lo que hace falta para que un libro pueda convertirse en un libro universal, un amigo para cada uno, y en especial ese expediente maestro de representar todo como habiendo sido ya descubierto, sin tener nada todavía en camino e incierto. Todo libro influyente intenta dejar atrás este tipo de impresión, para producir otra, la impresión de que aquí ha sido trazado el horizonte espiritual y psíquico más extenso, y de que toda estrella visible ahora o en el futuro tendrá que girar alrededor de lo que brilla aquí (VM §98).

Wagner también, para Nietzsche, tendría o habría tenido elementos de este mismo estilo omni-inclusivo y omni-comprehensivo, o universal, o 'fiel al amigo', tal como Allison ha caracterizado este logro estilístico. Nietzsche supo darle voz a este consolar fervoroso (alegres noticias), en la forma escrita y en la sustancia en su propio Así habló Zaratustra, planeado como una obra maestra y dirigido a un mundo que había dado una respuesta muy pobre -en cuanto que Nietzsche deseaba conseguir una respuesta notablemente sobrexcitada o al menos de estima- a sus primeros escritos. E incluso más importante que el ejemplo de esas propuestas análogas, recordemos el modelo muy exigente de

\footnotetext{
${ }^{48}$ La sorpresa se produce aquí sin duda sólo para los especialistas en Nietzsche que tienden a tomarlo como un 'completo' anti-cristiano, hasta el punto de oír únicamente sus más breves (y más populares) juicios en JGB §271.
} 
Nietzsche para la concisión de estilo, en expreso contraste con la reinante $-\mathrm{y}$ todavía perdurante- ampulosidad germánica en la expresión popular o en las extensas elaboraciones académicas de la misma ${ }^{49}$. Así como había celebrado el ideal del estilo griego en cuanto constreñimiento extremo -sus primeras prescripciones pedagógicas para la consecución de la forma poética y el estilo griegos es el de «danzar entre cadenas $»^{50}$-, Nietzsche hace valer después el icono romano del laconismo como inspiración: «Mi sentido del estilo, del epigrama como estilo», escribía Nietzsche en el Crepúsculo de los ídolos, «se despertó casi instantáneamente al entrar en contacto con Salustio» ${ }^{51}$.

La referencia al estilo extremo y enjuto de Salustio, como modelo del propio estilo nietzscheano, es una parte de la solución de cómo comprender el logro que supone el estilo de Nietzsche. ¿Qué quería decir con ello? La tesis de que no se puede sacar de un libro más de lo que ya conocemos - no hay nuevos descubrimientos para el Nietzsche que reflexiona sobre el estilo y el arte del lenguaje, leyendo a expertos como Gustav Gerber y muchos otros-, significa que Nietzsche era primero y ante todo un retórico y esto significa que él siempre estaba pensando en qué puede o podría oír el lector-o leer fuera o dentro-en sus textos. Por esta misma razón, como he argumentado aquí, es un signo elocuente de la tendencias positivistas de la ciencia filológica -que en nuestros días es en Alemania el estudio académico literario y la investigación de fuentes- que el

${ }^{49}$ En dos cortos apuntes del Nachlaß podemos encontrar: «Mein Styl hat eine gewisse wollüstige Gedrängtheit», y «Der Dichter muss ein Ding erst genau sehn und es nachher wieder ungenau sehen: es absichtlich verschleiern. Manche versuchen dies direkt; aber da gelingt's nicht (wie bei Schiller). Die Natur muss durch das Gewand durchleuchten» KSA VIII 291. Es aquello que él llama «Fiestas raras» en WS $§ 108$ : «Concisa compactación, pleno reposo y madurez - cuando encuentras en un autor estas cualidades párate y festeja una larga fiesta en medio del desierto: pasará mucho tiempo antes de que vuelvas a experimentar un sentimiento tal de bienestar».

${ }^{50} \mathrm{VM} \S 140$. En Humano, demasiado humano, la referencia de Nietzsche no es a la tradición estilística latina sino a la griega y a la época de Demóstenes, donde, igual que en Ecce homo, se abogaba por la concisión como profiláctico cultural: «La reflexión rigurosa, la limpieza, la frialdad, la simplicidad, deliberadamente convencidas hasta sus límites, la auto-contención de los sentimientos, y el silencio en general... eso sólo puede ayudarnos» MA $\$ 195$. Cf. también las reflexiones contenidas en un aforismo un poco más abajo, titulado «La revolución en poesía», $\$ 221$.

${ }^{51}$ GD X §1: «ein Sinn für Stil, für das Epigramm als Stil erwachte fastaugenblicklich bei der Berührung mit Sallust». Así continua resaltando «Ich habe das Erstaunen meines verehrten Lehrers Corssen nicht vergessen, als er seinem schlechtesten Lateiner die allererste Censur geben musste -, ich war mit Einem Schlage fertig» KSA VI 154. Nietzsche también invoca a Horacio para describir el estilo en palabras que él mismo reivindica para sus propios escritos: «Dies Mosaik von Worten, wo jedes Wort, als Klang, als Ort, als Begriff, nach rechts links und über das Ganze hin seine Kraft ausströmt, dies minimum von Umfang der Zeichen, dies damit erreichte maximum von Energie des Zeichens - das Alles ist römisch und, wenn man mir glauben will, vornehm par excellence: der ganze Rest von Poesie wird dagegen eine Gefühls-Geschwätzigkeit. Ich möchte am wenigsten den Reiz vergessen, der im Contrast dieser granitnen Form und der anmuthigsten Libertinage liegt: - mein Ohr ist entzückt über diesen Widerspruch von Form und Sinn» KSA XIII 624-625.

Estudios Nietzsche, 4 (2004), ISSN: 1578-6676, pp. 11-35 
descubrimiento de las referencias y alusiones eruditas de Nietzsche -a Lange o a Gerber, por nombrar los más conocidos de tales nombres- sea visto como un signo de dependencia o de redundancia, o mucho peor -y de modo absolutamente solecista, como he defendido- como un plagio intelectual o de ideas. Ignorantes del entrenamiento de Nietzsche en filología, carentes de lo que llamaría erudición, los lectores actuales imaginan que, para pensar creativa o filosóficamente, uno tiene que pensar algo absolutamente nuevo, algo nunca reflexionado antes. Con esta convicción somos 'Münchhausen del espíritu' -como Nietzsche nos llamaría (o llamaba).

Sobre la cuestión del plagio y de las deudas intelectuales, sobre la cuestión de individuar las fuentes, el escrito La filosofía de los griegos en su época trágica incluye una reflexión que anticipa esta tendencia actual, en cuanto que era una convicción creciente en su época. Para Nietzsche, lo que importa no es tanto la invención nueva o el descubrimiento inaudito, si es que la novedad es posible. En cambio, Nietzsche argumenta en nombre de los griegos, como hoy argumentaría en su propio nombre, que lo que importa es el aprendizaje fructífero, porque incluso las que creemos que son nuestras ideas más nuevas y más inauditas, llevan inevitablemente las marcas de influencias olvidadas, pisoteadas por, usando el término de Nietzsche para la verdad, un ejército de metáforas.

En un sentido pre-gadameriano, hermenéutico, Nietzsche no intentaría articular al autor mejor de lo que él (Nietzsche) se entendió a sí mismo, sino articular la inevitable proyección de nuestra propia comprensión de nosotros mismos y del texto en lo que llamamos 'interpretación' -interpretación bajo la cual el texto de Nietzsche no puede más que desaparecer (JGB §38). Desde el principio, Nietzsche se impone a sí mismo la tarea de resaltar lo que esas limitaciones de perspectiva, por el contexto, suponen para la filosofía y la lectura -esta es la tarea de la erudición, que Nietzsche no distingue de lo que nosotros seguimos pensando que es una ciencia-, y lo hace tanto en vista a sus lectores como en vista a superar esas mismas limitaciones. Pero además anota algo que enfatiza esta complejidad y la enlaza con los frutos de sus primeros planteamientos con respecto a la música no-oída pero no por ello no-oíble -se puede aprender a leer y, más aún, a oír la música- del texto: «Nuestro ojos oyen mucho más profundamente que nuestros oídos: tenemos mejor gusto y entendimiento cuando leemos que cuando escuchamos -en el caso tanto de libros como de música» ${ }^{52}$. Es decir: dada la calmada resonancia de los textos antiguos, dada la pureza de una partitura musical antes de cualquier ejecución para el oído, tenemos una oportunidad para conceptualizar y así 'oír' tanto los textos musicales antiguos como los contemporáneos, con la condición sólo de que nos hayamos esforzado en aprender, tal como Nietzsche resalta constantemente, el arte de leer. En este

\footnotetext{
${ }^{52}$ «Unsere Augen hören feiner als unsere Ohren: wir verstehen und schmecken lesend besser als hörend - bei Büchern wie bei Musik» KSA X 103.
}

Estudios Nietzsche, 4 (2004), ISSN: 1578-6676, pp. 11-35 
sentido podemos entender el breve aforismo «Una palabra de consuelo para el músico», de La gaya ciencia: «Tu vida no alcanza el oído de los hombres; tu vida es silenciosa para ellos y todas las sutilezas de su melodía, todas las delicadas resoluciones en el seguir o preceder permanecen escondidas para ellos. En verdad, tú no te aproximas por una ancha carretera con música militar, pero esto no les da ningún derecho a esa buena gente a decir que tu vida carece de música. Quien tenga oídos para oír, que oiga» (FW §234).

«Que los que tengan oídos oigan». La alusión bíblica es a la parábola del sembrador. Correspondientemente, Nietzsche la toma como su tarea de encontrar oídos respondientes, una imagen que refleja la conmovedora preocupación fetichista de Nietzsche por sus pequeñas orejas, tal como nos cuenta Lou Salomé y tal como nos cuenta en verso el mismo Nietzsche (Du hast kleine Ohren, Du hast meine Ohren (KSA VI 398)) y sus constantes invectivas contra las orejas largas de aquellos que él halló demasiado actuales -demasiado sordos ${ }^{53}$.

¿Entonces tenemos oídos hoy en día para Nietzsche? Deberíamos tenerlos no sólo para su poesía, sino también para su filosofía imbuida en y por su atractivo estilístico. ¿Somos capaces hoy de 'oír' Nietzsche como filósofo -por invocar el provocador sentido práctico del título del libro de Arthur Danto, ese importante primer libro de la ola creciente de apropiaciones analíticas de Nietzsche? ¿Qué podría ser oír a Nietzsche nuevamente como por primera vez, y no de manera vaga o gastada, casi 'como' filósofo, junto con todas las otras maneras en que Nietzsche puede ser oído cuando nos habla como uno que, en términos heideggerianos, sabe lo que es la filosofía.

traducción de Marco Parmeggiani Universidad de Málaga

\footnotetext{
${ }^{53}$ La imagen de los oídos y sus alusiones bíblicas son recurrentes en el Zaratustra (y quizás son más conocidas por ello), en el tercer libro, en el capítulo titulado «De la visión y el enigma». Allí, Nietzsche invita a sus lectores a identificarse con osados aventureros, es decir, con discípulos que se ven así a sí mismos, relacionándolo con la amistad de Zaratustra hacia aquellos que del mismo modo se ven a sí mismos como viviendo peligrosamente: «a vosotros ebrios de enigmas, que gozáis de la luz del crepúsculo, cuyas almas son atraídas por flautas a abismos traicioneros». Abogado de la valentía, Zaratustra ofrece una letanía de lo que puede ser la valentía, ella ataca, supera, destruye el vértigo ante el abismo, e invita al eterno retorno: «¿y dónde no se halla el hombre ante un abismo? ¿No es el ver mismo... ver abismos? [...] cuán profundo mira el hombre dentro de la vida, así de profundo mira también dentro del dolor [...] Pero la valentía es el mejor destructor, la valentía que ataca: destruye incluso la muerte, porque dice: “Esta fue la vida? ¡Muy bien, una vez más!” [...] Quien tenga oídos para oír, que oiga». Y de nuevo en el capítulo «De las viejas y nuevas tablas» (\$17) oímos a Zaratustra declarar «Y vosotros primero tenéis que aprender también de mí cómo escuchar, cómo escuchar bien - quien tenga oídos para oír que oiga». Finalmente vuelve a aparecer en El caso Wagner, §10: con respecto al ingenio (Klugheit) de Wagner: «El sistema de los procedimientos que Wagner usa es aplicable a cien otros casos: que quien tenga oídos, oiga». Para las expresiones en la Biblia, cf. Mt 13:9; 13:43 y Mc 4:9, etc.
} 